\title{
ANÁLISE DO PROCESSO DE PROFISSIONALIZAÇÃO DA GESTÃO DE EMPRESAS FAMILIARES ATUANTES NO VAREJO
}

\section{1- Harrison Bachion Ceribeli*}

Mestrando em Administração pela Faculdade de Economia, Contabilidade e Administração de Ribeirão Preto (FEARP/USP)

Programa de Pós-Graduação de Administração de Organizações da Faculdade de Economia, Contabilidade e Administração de Ribeirão Preto (FEARP/USP), Ribeirão Preto/SP, Brasil. harrisonbceribeli@yahoo.com.br

\section{2- Edgard Monforte Merlo}

Doutorado em Administração e Livre-Docência pela Universidade de São Paulo (USP) Programa de Pós-Graduação de Administração de Organizações da Faculdade de Economia, Contabilidade e Administração de Ribeirão Preto (FEARP/USP), Ribeirão Preto/SP, Brasil. edgardmm@usp.br

\section{3- Frank da Silva Morais}

Mestrando em Administração pela Faculdade de Economia, Contabilidade e Administração de Ribeirão Preto (FEARP/USP)

Programa de Pós-Graduação de Administração de Organizações da Faculdade de Economia, Contabilidade e Administração de Ribeirão Preto (FEARP/USP), Ribeirão Preto/SP, Brasil. frankmorais@hotmail.com 


\title{
ANÁLISE DO PROCESSO DE PROFISSIONALIZAÇÃO DA GESTÃO DE EMPRESAS FAMILIARES ATUANTES NO VAREJO
}

\section{RESUMO}

Muitos varejistas foram fundados como pequenas empresas, cuja gestão estava concentrada nos sócios, de maneira informal; entretanto, cresceram e atingiram um nível no qual a gestão familiar e informal não mais é eficiente. Assim, muitos proprietários perceberam a necessidade de profissionalizar a gestão de suas empresas, preparando-as para continuar a crescer. Este trabalho teve como objetivo estudar o processo de profissionalização da gestão nas empresas varejistas familiares e suas implicações gerenciais, explorando com maior profundidade aspectos-chave inerentes a este processo. Foram desenvolvidos dois estudos de casos envolvendo a profissionalização da gestão de dois grupos varejistas. Posteriormente, os autores elaboraram uma série de proposições acerca do processo estudado. Constatou-se que a iniciativa rumo à gestão mais profissional dos negócios deve partir dos sócios da organização, que devem substituir o controle operacional pelo planejamento. Deve-se citar também que uma estrutura administrativa mais profissional facilita a implementação de ações e práticas mais modernas de gestão. Também merece destaque neste processo a necessidade de estruturar um organograma formal de gestão e de estabelecer um sistema de controle mais amplo, transformando o controle micro, focado em atividades, em controle macro, focado em resultados.

\section{Palavras-Chave}

Profissionalização; gestão familiar; varejo.

\section{ANALYSIS OF THE PROFESSIONALIZATION PROCESS OF MANAGEMENT OF FAMILY BUSINESS OPERATING IN RETAIL}

\begin{abstract}
Many retailers was founded as a small business, whose management was concentrated in the partners. However, grew and reached a level at which family and informal management no longer is efficient. Thus, many owners saw the need to professionalize the management of their businesses, preparing them to continue to grow. This study aimed to explore the process of professionalization of management in retail companies and their managerial implications, exploring in greater depth some key aspects inherent in this process. Were analyzed two case studies involving the professional management of two retail groups. Subsequently, were developed a series of propositions about the observed process. It was found that the initiative for a more professional business must originate from the organization's owners, who must replace the operational control by planning. It is worth mentioning that a more professional management structure facilitates the implementation of actions and practices of modern management. It should also be highlighted in this process the need to structure a formal organizational structure of management and establish a wider control system, transforming the control micro, focused on activity, in macro control, focused on results.
\end{abstract}

\section{Keywords}

Professionalization; family management; retail. 


\section{Introdução}

Segundo McGoldrick (2002), uma tendência no varejo é o crescimento e o aumento do poder das empresas varejistas.

Relacionado a esta tendência, muitas organizações que atuam no segmento de varejo vivenciam atualmente um grande dilema: tiveram início como pequenas empresas, administradas de maneira informal pelos próprios fundadores e familiares, concentrando o processo decisório; entretanto, alcançaram níveis elevados de crescimento e atingiram um ponto em que não é mais possível manter o tradicional sistema familiar e informal de gestão.

À medida que estas empresas crescem, os desafios tornam-se mais complexos, e a necessidade de controle de cada atividade operacional perde espaço para a necessidade de planejamento de médio e longo prazo.

Com isso, a atual estrutura de gestão informal não alcança a amplitude e os níveis de abstração necessários, e, ao mesmo tempo, sobrecarrega os sócios da empresa.

Sendo assim, teve início um movimento no sentido de profissionalizar a gestão destas empresas familiares, de modo a criar uma estrutura administrativa que prepare a organização para os desafios de se tornar uma empresa maior e mais dinâmica, e que a torne capaz de gerenciar a complexidade inerente ao processo de crescimento.

No entanto, apesar de ser um tema atual e relevante, a literatura acadêmica não aborda de maneira precisa o processo de profissionalização de empresas varejistas cuja gestão ainda é familiar, e os benefícios resultantes deste processo.

Por isso, este trabalho teve como objetivo estudar o processo de profissionalização de empresas varejistas, e suas implicações gerenciais, de maneira a explorar com maior grau de profundidade alguns aspectos-chave inerentes a este processo, e fornecer uma base sólida para pesquisas futuras.

\section{Metodologia}

A metodologia empregada nesta pesquisa é composta por uma pesquisa bibliográfica, que, segundo Cooper e Schindler (2003), consolida a fundamentação teórico-metodológica do trabalho, e, posteriormente, por uma pesquisa de projetos de casos múltiplos, que, segundo Yin (2005), é uma forma de se realizarem vários estudos de casos relacionados, de maneira a buscarem-se evidências mais relevantes e convincentes em relação aos resultados obtidos pela utilização de um estudo de caso isolado.

Os objetos dos estudos de casos múltiplos foram dois grupos varejistas brasileiros, um atuando apenas no setor supermercadista e o outro atuando em diversos setores, que possuem faturamento de $R \$ 50$ milhões e $R \$ 40$ milhões, respectivamente, sendo que, no caso do grupo que possui investimentos diversificados, o faturamento apresentado anteriormente corresponde apenas às atividades supermercadistas do grupo.

A escolha destes supermercados seguiu o método de amostragem não probabilística por conveniência, pois esta forma de amostragem atende uma abordagem subjetiva de pesquisa e possibilita ao autor maior liberdade de escolha dos casos a serem estudados (COOPER; SCHINDLER, 2003; GIL, 2001).

Deve-se citar que os autores optaram pelas duas organizações varejistas em questão devido a três fatores: (1) pela representatividade regional de ambas no segmento supermercadista do Estado de Goiás; (2) pelo conhecimento prévio dos pesquisadores acerca da situação daquelas, ou seja, de que aquelas empresas estariam iniciando o processo de profissionalização; e (3) pela abertura dada aos pesquisadores pelos executivos destas empresas para acompanharem os processos de profissionalização das mesmas.

Sendo assim, foram desenvolvidos dois estudos de casos (Yin, 2005), que englobaram o acompanhamento dos processos de profissionalização da gestão, inicialmente familiar, de ambos os grupos.

Os instrumentos de pesquisa utilizados foram observação direta e entrevistas com os membros da alta administração que participaram dos processos de profissionalização estudados. 
As entrevistas em profundidade realizadas com todos os sócios e executivos participantes do processo de profissionalização seguiram roteiros semi-estruturados; no entanto, os entrevistados foram encorajados a extrapolar as questões delimitadas no roteiro, de modo que pudessem expressar perspectivas e pontos de vistas em relação ao processo de profissionalização que vivenciaram.

Além disso, um dos pesquisadores autores deste trabalho teve a oportunidade de acompanhar todo o processo de profissionalização em cada uma das organizações estudadas, elevando a qualidade das informações coletadas. Isto se deu devido ao fato de que aquele obteve permissão dos executivos de cada uma da empresas para acompanhar todas as atividades desenvolvidas e os respectivos resultados. No entanto, cabe ressaltar que não houve atuação direta do pesquisador nas realidades estudadas, limitandose sua participação à observação do contexto organizacional e do processo de profissionalização.

As etapas do estudo desenvolvido aqui foram:

1 Identificação das empresas que estariam passando por um processo de profissionalização de sua gestão e contato inicial;

2 Diagnóstico da situação inicial das organizações escolhidas, contextualizando o processo de profissionalização e identificando pontos para comparação com os resultados que seriam alcançados no final do processo;

3 Acompanhamento de todas as decisões tomadas e mudanças propostas, de maneira a separar as ações idealizadas das ações implementadas;

4 Análise dos resultados obtidos com cada ação implementada e das dificuldades/obstáculos encontrados para operacionalizar as decisões tomadas;

5 Comparação das constatações obtidas em cada um dos estudos de caso, de modo a desenvolver um relatório conjunto, identificando semelhanças e pontos divergentes;

6 Análise das constatações obtidas por meio desta comparação e desenvolvimento de proposições teóricas.

Neste sentido, depois de analisarem os estudos de caso, os autores delimitaram oito proposições acerca dos processos de profissionalização de gestão de varejos familiares. Estas proposições foram então discutidas com base no referencial teórico pesquisado, para que posteriormente fossem apresentadas as conclusões desta pesquisa.

\section{Revisão Bibliográfica}

\section{O Varejo}

De acordo com Kotler (2000), uma organização pode ser considerada como um varejista se a maior parte de seu faturamento for proveniente da venda de pequenos lotes para o consumidor final. Já Levy e Weitz (2000) defendem que o varejista é o último elo entre a cadeia produtiva e o cliente final, ou seja, é o elo da cadeia de suprimentos que liga fornecedores e consumidores. Uma última definição que deve ser citada é que "Varejo consiste em todas as atividades que englobam o processo de venda de produtos e serviços para atender a uma necessidade pessoal do consumidor final" (PARENTE, 2009, p.22).

Parente (2009) cita que o volume de vendas no varejo brasileiro supera $R \$ 100$ bilhões anuais, e que a atividade varejista representa mais de $10 \%$ do PIB do Brasil. Estes números mostram a importância que o setor varejista possui no cenário nacional.

E uma categoria específica dentro do varejo é a de varejo de alimentos, e dentro desta categoria, o varejo supermercadista. Os varejistas de alimentos são aqueles que comercializam um grande número de produtos alimentícios dispostos em formato self-service e com check-outs na saída (SANTOS; COSTA, 1997). De acordo Parente (2009), no Brasil, o varejo de alimentos, notadamente hipermercados, supermercados, lojas de conveniência, lojas de especialidades entre outros, são importantes tanto para economia, quanto para a estratégia de distribuição.

Um supermercado pode ser compacto ou convencional, sendo que o primeiro normalmente está relacionado a varejistas independentes, enquanto que o segundo é operado por redes de varejo. 0 Supermercado compacto, de acordo com Parente (2009), é caracterizado pelo sistema de auto-serviço, 
pela presença de check-outs e pela disposição dos produtos de maneira acessível para os clientes. Além disso, um supermercado compacto possui uma linha completa, apesar de compacta, dos produtos alimentícios e disponibiliza de dois a seis check-outs nas saídas das lojas.

Já os supermercados convencionais são "supermercados de médio porte, que mantêm o caráter essencialmente de loja de alimentos, apresentando boa variedade de produtos" (PARENTE, 2009, p.32). Este autor ainda afirma que, no Brasil, a maioria das redes de varejo opera com sistemas de supermercados convencionais.

Kotler (2000), entretanto, afirma que uma tendência do setor varejista é a concorrência estender-se entre varejos com diferentes formatos, ou seja, a concorrência não se limitará mais apenas aos supermercados convencionais e compactos. Superlojas, hipermercados, clubes atacadistas, todos os formatos varejistas competem, no mercado atual, pelos mesmos consumidores que os supermercados, compactos ou convencionais.

\section{Empresas Familiares}

\subsubsection{Definição e caracterização}

Empresa familiar pode ser definida, segundo Donnelley (1967), como aquela que esteja ligada a uma família por, pelo menos, duas gerações, exercendo forte influência sobre as diretrizes empresarias.

Leone et al. (1996) explicam que uma empresa familiar deve ter seu início marcado pela participação direta de uma família, a qual deve estar presente na direção da organização, possuindo um vínculo em relação à propriedade da mesma.

Bernhoeft (1996) lista as seguintes características presentes nas empresas familiares: (1) forte valorização da confiança mútua; (2) laços afetivos que influenciam comportamentos e decisões; (3) valorização da antiguidade ou tempo de serviço; (4) dificuldades em separar emocional e racional; e (5) expectativa de que os funcionários sejam altamente dedicados e fiéis à organização e a seus valores.

Para Lee (2004), um negócio familiar é aquele no qual uma família tem propriedade ou controle significativo; e, conforme indica Grzybovski (2002), uma empresa familiar é marcada por um modelo de gestão burocrático e pouco transparente, cuja tomada de decisão é centralizada geralmente no fundador.

Uma organização familiar, segundo Chua et al. (1999), deve ser caracterizada por ser um negócio gerenciado com a intenção de se manter e perseguir uma visão de negócios que corresponda aos valores dos membros de uma família, que mantém o controle da empresa, e busca sua sustentabilidade por meio de outras gerações familiares.

Steier e Ward (2006) destacam que as empresas familiares diferenciam-se das demais nas dimensões estratégicas e organizacionais, já que, no primeiro caso, a família influi de maneira direta e significativa no comportamento e futuro da organização.

De acordo com Gonçalves (2000), em empresas familiares, devem ser destacados alguns pontos que merecem atenção especial, já que, quando estas empresas alcançam um determinado nível de maturidade, aqueles podem representar alguns pontos críticos que se tornam obstáculos para o crescimento: (1) a estrutura informal de gestão; (2) a valorização da confiança e do tempo de serviços antes da competência; (3) o nepotismo, que pode prejudicar a profissionalização; e (4) a falta de planejamento de longo prazo.

\subsubsection{Ciclo de vida das empresas familiares}

Segundo Lodi (1989) as empresas familiares apresentam quatro fases de vida, as quais o autor denominou de ciclos de vida da empresa familiar (figura 01), a saber: (1) fundação, (2) crescimento, (3) apogeu, (4) declínio. Oliveira (1999) explica que os ciclos de vida da empresa familiar estão diretamente associados aos processos sucessórios e que os sucessores podem assumir a empresa em situações desfavoráveis ao longo do referido ciclo.

Chittoor e Das (2007) acrescentam que os eventos de sucessão podem ocorrer em dois sentidos básicos: (1) a passagem da direção do empreendimento para uma próxima geração da família ("passagem 
do bastão") ou (2) a passagem da direção do negócio para um gestor de fora da família (profissionalização da gestão).

Figura 1 - Os ciclos de vida da empresa familiar.

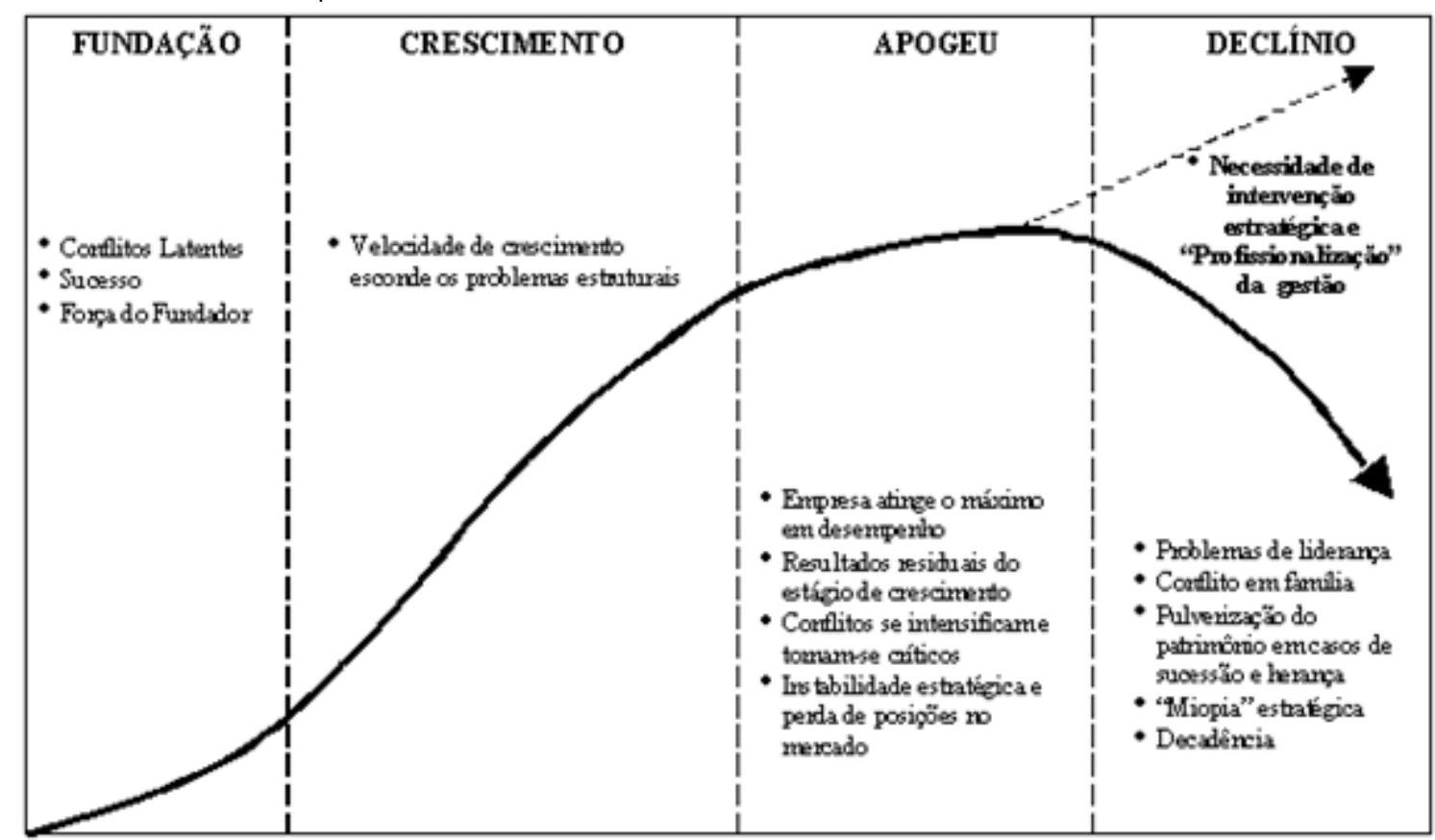

Fonte: Baseado em Lodi (1989).

Upton, Teal e Felan (2001) chamam a atenção para o fato de que as pesquisas sobre empresas familiares têm focado mais na análise dos processos sucessórios e menos em processos de planejamento e gestão do negócio, sendo estes últimos igualmente importantes em termos de sobrevivência, continuidade e competitividade do empreendimento familiar.

Por outro lado, estes mesmos autores observam que grande parte das pesquisas voltadas para o aspecto de gestão do negócio demonstra que é característica gerencial comum das empresas familiares a não realização de processos de planejamento do negócio e planejamento estratégico formal.

Ainda nessa linha, Upton, Teal e Felan (2001) verificaram que, em uma grande amostra de empresas familiares, algumas apresentavam um desempenho mercadológico muito acima da média setorial para aquele perfil de empresas. Os autores investigaram mais profundamente as razões para esse fenômeno e observaram que o grupo com desempenho baixo ou mediano apresentava características de "privacidade", isto é, não utilizavam gestores externos à família, não realizavam planejamento estratégico formal e não apresentavam relatórios e informações sobre a empresa. Isto para não expor a cultura, os valores e as estratégias competitivas da empresa. Por outro lado, as empresas pertencentes ao grupo que apresentou alto crescimento e desempenho mercadológico realizavam atividades de planejamento estratégico com frequência, com horizonte de tempo variando entre um e três anos. Além disso, as empresas deste grupo utilizavam gestores oriundos de fora da família para atividades de gestão e planejamento e também divulgavam informações e relatórios de gestão entre os stakeholders da organização.

As constatações de Upton, Teal e Felan (2001) parecem explicar algumas das possíveis limitações e problemas que as empresas enfrentam nas "fases" do seu ciclo de vida, apresentados na figura 01. A dinâmica de crescimento pode exigir da empresa familiar competências de planejamento estratégico para sustentar o processo de crescimento, bem como competências de gestão profissional do negócio para garantir o alcance dos seus objetivos e continuidade do negócio ao longo do tempo. Desse modo, é necessária uma discussão mais direcionada para o processo de profissionalização de empresas familiares. 


\section{3. Profissionalização de Empresas Familiares}

Existem dois estilos gerenciais que caracterizam as empresas familiares no tocante à forma de gestão: o estilo paternalístico e o estilo profissional de gestão. O primeiro é caracterizado pelas relações hierárquicas, controle do poder e da autoridade pelo dirigente, proximidade de supervisão e não confiança em "estranhos" (membros externos não pertencentes à família). O segundo envolve não só a inclusão, como também certa predominância de membros externos à família em posição de direção (LUSSIER; SONFIELD, 2004).

Lussier e Sonfield (2004) explicam que os fundadores possuem todo o espírito empreendedor e a criativa que originam o negócio e sua gestão é fortemente baseada em mecanismos informais e abordagens intuitivas de gestão. Ao passo que, à medida que as novas gerações da família vão assumindo o negócio e o empreendimento vai consolidando seu crescimento, torna-se crítico o uso de abordagens gerenciais mais formais, orientadas para resultados.

Conforme apresentado na figura 01, quando a empresa está sobre a gestão do fundador, os valores familiares e empresariais geralmente se confundem. Com o crescimento da empresa, evidencia-se o conflito entre o objetivo da família (principal stakeholder) e a sustentação do crescimento e da competitividade da empresa.

Em um estudo com 104 empresas, Daily e Dollinger (1992) identificaram que as empresas geridas profissionalmente confiavam mais em procedimentos de controle interno do que as empresas geridas pela família.

A autoridade da tomada de decisão também se modifica à medida que essa complexidade aumenta. No estágio da fundação, o fundador concentra a autoridade e centraliza a tomada de decisão, ao passo que à medida que novas gerações da família vão assumindo o negócio ocorre maior delegação de poder e descentralização da decisão (LUSSIER; SONFIELD, 2004).

Lussier e Sonfield (2004) destacam que a necessidade de profissionalização nas empresas familiares está relacionada com o avanço no estilo gerencial, saindo de uma abordagem paternalística e orientandose para uma abordagem profissional. Segundo os autores essa mudança de abordagem é condição necessária para suportar os eventos de crescimento da empresa. Na abordagem profissional são enfatizados dois elementos, ambos remetendo a formas mais profissionais de gestão: (1) planejamento estratégico e (2) sofisticação das técnicas gerenciais.

\section{Mudança Organizacional}

A profissionalização de empresas familiares pode ser caracterizada como um processo de mudança organizacional, o que faz com que se torne necessário estudar quais as características e peculiaridades presentes nas práticas de gestão de mudanças nas empresas.

\section{Mudança e resistências}

Segundo Chiavenato (1996, p. 24), “Mudança é a passagem de um estado para outro. É a transição de uma situação para outra situação diferente. Mudança representa transformação, perturbação, interrupção, fratura".

Segundo Walker, Armenakis e Bernerth (2007), as mudanças organizacionais podem ser classificadas em fundamentais, quando alteram o caráter da organização, e incrementais, quando apenas complementam outras mudanças realizadas anteriormente. Da mesma forma, estes autores classificam as mudanças como pontuais ou contínuas, sendo as primeiras infreqüentes e intencionais, e as segundas de caráter constante.

Já para Motta (1997), as mudanças organizacionais podem ser analisadas de acordo com diferentes perspectivas: perspectiva estrutural (focada nas estruturas de responsabilidade e autoridade formais); perspectiva tecnológica (utilização de recursos materiais e intelectuais, além de alteração de processos produtivos e tecnologia); perspectiva estratégica (baseada na redefinição da missão e objetivos empresariais, e formas pelas quais as organizações planejam suas ações); perspectiva humana (atitudes, comportamento e a forma de participação dos indivíduos); perspectiva cultural (a internalização de novos 
valores, na busca de um novo senso de identidade organizacional); e perspectiva política (redistribuição do poder dentro da empresa).

No entanto, um dos maiores obstáculos para a implementação bem-sucedida de mudanças nas organizações é um processo social conhecido como resistência à mudança.

De acordo com Lewin (1952), “A resistência à mudança seria o resultado da tendência de um indivíduo ou de um grupo a se opor às forças sociais que objetivam conduzir o sistema para um novo patamar de equilíbrio".

Robbins (2004) explica que a resistência parte tanto dos indivíduos quanto da própria organização. Segundo ele, em algumas situações, a resistência tem seu lado positivo, pois é a mesma que traz estabilidade e previsibilidade ao comportamento organizacional, além de trazer discussões sobre determinadas decisões, resultando em uma decisão melhor. Porém, a resistência tende a dificultar a adaptação e o progresso de uma empresa.

Robbins (2004) divide a resistência em duas categorias, sendo a primeira individual e a outra a nível organizacional. A resistência por parte dos membros da empresa ocorre por várias razões, entre elas o hábito (o ser humano tende a responder frente à mudança como tem costume de fazê-lo); a segurança (mudanças fazem com que as pessoas sintam-se ameaçadas); fatores econômicos (quando há dúvida a respeito de queda de rendimentos pessoais com a mudança); medo do desconhecido (em um processo de mudança, o que era conhecido passa a ser ambíguo e incerto); e por causa do processo seletivo de informações (para não mudarem suas percepções de mundo, os indivíduos tendem a ignorar informações que possam questionar suas formas de pensar).

Já a resistência organizacional ocorre pelos seguintes motivos: inércia estrutural (a própria estrutura da empresa tende a manter a estabilidade, através de processos de seleção que dão preferência a certas características pessoais na contratação, ou por meio de treinamentos que visam socializar novos funcionários, entre outros exemplos); foco limitado de mudança (como os sistemas que formam uma organização são interdependentes, mudanças que se limitam a alguns subsistemas tendem a ser anuladas pelos demais); inércia do grupo (geralmente as normas grupais influenciam iniciativas de mudanças de comportamentos a nível individual); ameaça à especialização (algumas mudanças ameaçam certos grupos especialistas em determinados assuntos); ameaça às relações de poder estabelecidas (mudanças podem representar redistribuição de autoridade dentro da organização); ameaça às alocações de recursos estabelecidas (mudanças podem representar realocações de recursos organizacionais, fazendo com que determinados grupos que antes eram beneficiados sintam-se ameaçados) (ROBBINS, 2004).

\section{Gerenciamento do processo de mudança organizacional}

De acordo com Megginson, Mosley e Pietri (1991), um processo de mudança organizacional inicia-se quando forças externas e internas exercem pressão sobre a alta administração de determinada empresa. Isso faz com que a cúpula da organização reoriente sua atenção para os problemas internos, de modo a realizar um diagnóstico das áreas com problemas. Após a identificação de disfunções organizacionais, começa uma busca por novas idéias, por novas soluções, as quais são experimentadas, de forma a analisar os resultados dessas novas ações. Finalmente, se as mudanças geraram melhorias, esse resultado positivo torna-se um reforço positivo, de modo a garantir a aceitação das novas práticas.

Um outro processo mais detalhado relacionado à gestão de mudanças nas empresas é descrito por Kotter (1997), que buscou dividir o processo em oito etapas, e que tem como resultado, segundo o autor, a implementação bem-sucedida de mudanças nas organizações.

Segundo Kotter (1997), gerir uma mudança torna-se tão complicado porque requer muita cooperação, iniciativa e sacrifício por parte de todas as pessoas envolvidas. Sendo assim, a primeira etapa de qualquer esforço de mudança deve ser o estabelecimento de um senso de urgência, e isso só é conseguido através da remoção de fontes de complacência, que são a principal causa do não comprometimento das pessoas com o processo de mudança.

Kotter (1997) lista algumas fontes de complacência, como, por exemplo, falta de feedback externo acerca do desempenho da empresa; sistemas errôneos de avaliação interna; otimismo elevado da alta administração; além de uma cultura organizacional que busca evitar conflitos e más notícias, entre outras. 
Quando um senso de urgência é desenvolvido entre os membros da organização, estes tendem a esforçarem-se mais em busca de quebrarem o status quo.

A segunda etapa consiste na formação de uma coalizão de pessoas com autoridade suficiente para liderar a mudança. Esta equipe deve também ser formada por pessoas especialistas em diversas áreas, de modo a garantir elevado grau de informação de toda a equipe, que possuam boa credibilidade perante outros membros da empresa, e que tenham a habilidade de liderança, para conduzirem o processo.

O próximo passo é o desenvolvimento de uma visão que possa direcionar os esforços de mudança, e a elaboração de uma estratégia, que permite com que a visão seja concretizada. A visão refere-se a um quadro futuro, além de explicitar a razão que torna esse quadro melhor que o atual. Já a estratégia explica como essa visão será concretizada. O autor reforça, no entanto, que a elaboração da visão deve sempre considerar a viabilidade da mesma, sendo que muitas das visões corporativas atuais não passam de um sonho que não pode ser concretizado.

A quarta etapa é conseqüência da elaboração da visão, pois consiste na comunicação desta visão para todos os envolvidos nos esforços para mudar. Uma grande visão pode servir como um propósito útil mesmo que seja entendida por apenas algumas pessoas fundamentais. Mas o poder real de uma visão é revelado apenas quando a maioria dos envolvidos em uma empresa ou atividade tem um entendimento comum de seus objetivos e direção. Esse senso compartilhado de um futuro desejável pode ajudar a motivar e coordenar os tipos de ações que provocam transformações (KOTTER, 1997). O autor ainda lembra que, apesar de ser uma tarefa árdua essa comunicação, os responsáveis pela mesma devem sempre buscar a clareza e a simplicidade da mensagem.

Para Walker, Armenakis e Bernerth (2007), uma mensagem eficaz deve conter cinco elementos: a relação entre o estado atual e o desejado; como a mudança proposta é apropriada para eliminar a diferença entre ambos; a confiança que os agentes da mudança têm na implementação bem-sucedida da mudança; a confirmação do envolvimento da alta administração no processo; e, finalmente, os benefícios, para os colaboradores, que serão obtidos com a mudança.

O passo seguinte baseia-se no empowerment, ou seja, munir os colaboradores de autoridade para que eles possam agir quando necessário. Juntamente a isso, os funcionários devem receber treinamento para que possam preparar-se para maiores responsabilidades consequentes com a maior delegação por parte dos superiores.

O sexto passo é o desenvolvimento de um projeto de mudança que possibilite conquistas em curto prazo, pois estas fomentam a credibilidade necessária para que os esforços da mudança sejam mantidos no longo prazo. As conquistas em curto prazo são importantes para evidenciar que o projeto está realmente gerando resultados, e, sem isso, manter a motivação dos envolvidos pode tornar-se uma tarefa bastante complicada. Além disso, ao programarem-se conquistas a curto prazo, aumenta a pressão sobre as pessoas para que atinjam estas metas, o que mantém o senso de urgência, descrito no passo um do processo, nas pessoas envolvidas.

A penúltima etapa consiste na consolidação de ganhos e produção de mais mudanças. Nesta fase do processo, o foco volta-se para impedir que forças contrárias à mudança ganhem poder, pois com o passar do tempo, a tendência é que o nível de complacência da equipe responsável por dirigir os esforços de mudança e de todos os demais envolvidos aumente. Para evitar isso, além dos resultados de curto prazo, os líderes devem impedir que haja uma parada ou um descanso em relação à estratégia traçada, pois um pequeno desvio pode gerar um retrocesso em todas as mudanças conseguidas até então. Além disso, nesta fase do processo, vários projetos de mudança devem ser iniciados, pois à medida que o projeto principal se desenvolve, vários elementos são identificados como necessitando de transformações.

E, por fim, na última fase do processo, buscam-se alterações na cultura organizacional, sendo que Kotter define cultura como sendo "Normas de comportamento e valores compartilhados entre um grupo de pessoas" (KOTTER, 1997, p. 150).

“Quando as novas práticas criadas em um esforço de transformação não são compatíveis com as culturas relevantes, sempre estarão sujeitas ao retrocesso" (KOTTER, 1997, p. 150).

E, apesar de várias teorias afirmarem a necessidade de iniciar-se um processo de mudança pela cultura, Kotter (1997) defende que uma cultura só muda depois que as ações das pessoas tenham sido alteradas 
com sucesso, depois que o novo comportamento produziu resultados e depois que as melhorias geradas sejam ligadas às mudanças implementadas.

Concluindo a oitava etapa do processo proposto por Kotter, este afirma que mesmo que as mudanças de comportamento e atitude comecem no início do processo, estas só são fixadas na cultura no final do ciclo da mudança.

\section{Estudos de Casos}

\section{Grupo A}

Após obter uma sequência de resultados negativos nos anos anteriores, o grupo varejista A, que atua unicamente no segmento supermercadista, cujo faturamento girava em torno de $\mathrm{R} \$ 50$ milhões por ano, optou por profissionalizar sua gestão, cuja direção estava centralizada em seu proprietário e presidente, que era aconselhado de maneira informal por um irmão e um consultor financeiro.

O grupo carecia de uma diretoria executiva, e de profissionais qualificados e especializados, já que não havia uma estrutura para planejamento e tomada de decisão.

A iniciativa de criar um conselho de gestão profissional partiu do presidente do grupo, que, além de se encontrar extremamente saturado pela concentração de responsabilidades, não sabia como reverter os prejuízos que vinham ocorrendo nos últimos anos.

O processo de profissionalizar a administração do grupo teve início com a contratação de dois executivos, especializados na gestão comercial em varejo supermercadista e em tecnologia da informação, respectivamente. Posteriormente, o gerente contábil-financeiro e o gerente de recursos humanos de uma das lojas do grupo foram promovidos para cargos de gestores, ocupando o mesmo nível hierárquico dos executivos recém-contratados.

O presidente do grupo, que continuou sendo o proprietário, juntamente com os quatro novos gestores e com os dois conselheiros, agora formalmente participantes da administração do grupo, formou o conselho de gestão, cuja posição hierárquica era superior à posição que ocupava cada um de seus membros individualmente.

Estruturado o conselho, a primeira ação desenvolvida consistiu na criação de um organograma formal e explícito, de modo a favorecer a atribuição de responsabilidades e poder, já que, como não existia qualquer instrumento formal de divisão de autoridade e responsabilidades, ninguém assumia erros ou era formalmente cobrado por resultados, além de que, muitas vezes, a organização pecava por omissão de seus colaboradores.

Cada gestor tinha autonomia dentro de sua área de competência, de modo que a organização passou a descentralizar a tomada de decisão, agilizando o processo decisório e a implementação de programas que visavam a recuperação dos resultados operacionais.

Todas as lojas do grupo, que possuíam gerentes operacionais, eram subordinadas ao conselho de gestão, que estabeleceu critérios lógicos para a tomada de decisão, e elaborou uma política de negócios para direcionar o planejamento e as decisões de cunho estratégico, que passaram a ser discutidas em reunião semanal do conselho.

O desenvolvimento de um sistema de planejamento e controle, operacionalizado por meio da orçamentação anual, permitiu aos gestores e presidente da organização que mensurassem periodicamente os resultados obtidos, por meio da confrontação entre orçado e realizado. Desta forma, quedas no desempenho das vendas eram rapidamente sinalizadas, o que permitia que os gestores adotassem ações rápidas, de modo a sanar quaisquer deficiências.

Duas outras medidas, consideradas pelos membros do conselho de gestão como fundamentais para a profissionalização do grupo e recuperação da rentabilidade, foram a integração interdepartamental, entre as lojas e dentro de cada loja, e a demissão de vários gerentes-médios, que resistiam ao novo paradigma organizacional, no qual o desempenho substituiu o antigo critério de recompensa, baseado em tempo de serviço. 
Para integrar o grupo, foi implantado um software de planejamento que considera todos os recursos organizacionais, conhecido como Enterprise Resource Planning ou ERP, que aumentou a transparência na gestão, tanto pelas informações em tempo real fornecidas, quanto pelos relatórios gerenciais emitidos com base nestas informações constantemente atualizadas.

Algumas mudanças importantes que resultaram do processo de profissionalização do grupo varejista estão demonstradas no quadro 01.

Dentre estas mudanças, vale destacar as alterações ocorridas no setor de compras, já que antes da reestruturação gerencial, mais de $80 \%$ das compras eram negociadas com distribuidores e atacadistas, o que reduzia muito a margem de lucro do grupo, que passou a negociar mais de $80 \%$ das compras diretamente com as indústrias fabricantes, o que diminuiu drasticamente o custo da mercadoria vendida.

Quadro 1 - Antes e depois da profissionalização do grupo

\begin{tabular}{ll}
\hline Antes & Depois \\
\hline Mudanças constantes no layout das lojas & Layout pré-definido e melhor planejado \\
Mix de produtos pouco variado & Mix de produtos variado horizontal e verticalmente \\
Atendimento que originava muitas reclamações & Atendimento cordial, com foco no cliente \\
Colaboradores com pouco conhecimento funcional & Colaboradores com domínio das funções exercidas \\
Equipamentos ultrapassados & Modernização dos equipamentos \\
Estoque elevado & Estoque com alto giro \\
Compras realizadas por meio de distribuidores & Compras realizadas frente às indústrias \\
Funções de marketing distribuídas & Criação de um departamento de marketing \\
\hline Fonte: elaborado pelos autores com base nesta pesquisa
\end{tabular}

Fonte: elaborado pelos autores com base nesta pesquisa

Esta alteração foi resultado da implantação de um sistema de avaliação de desempenho, que, como dito anteriormente, substituiu a antiga estrutura baseada em tempo de serviço, e passou a avaliar o desempenho de cada comprador baseado nas negociações fechadas.

Além disso, a mudança no atendimento também foi extremamente relevante, pois o grupo, que antes possuía muitas reclamações com relação ao atendimento ruim e à falta de qualificação dos funcionários, que não forneciam informações corretas para os clientes, recebeu um prêmio de reconhecimento pelo atendimento de qualidade que passou a ser referência em uma das cidades onde o grupo montou uma loja.

Ao final de 2005, um ano após o início do processo de profissionalização do grupo, a organização obteve o maior lucro operacional de sua história, o que favoreceu a continuidade dos esforços no sentido de profissionalizar a gestão empresarial e buscar práticas modernas de administração no varejo.

Os membros do conselho de gestão afirmam que a grande mudança que permeou a organização foi a ruptura de um paradigma de gestão baseado no empirismo, que deu lugar para o desenvolvimento de um planejamento formal, criação de diretrizes, prestação de contas, estabelecimento de metas e controle constante.

Isso, juntamente com o comprometimento e cumplicidade dos gestores, foram os aspectos-chave no processo de profissionalização estudado.

Além disso, deve-se citar que a comunicação efetiva entre os membros do conselho, e entre este e os demais níveis hierárquicos, favoreceu o desenvolvimento de um ambiente onde a transparência e o comprometimento propiciaram a implementação de mudanças tão radicais, sem que houvessem grandes choques na cultura organizacional do grupo varejista em estudo.

\section{Grupo B}

Este grupo empresarial, dirigido por cinco sócios, todos irmãos, sem qualquer formação técnica em administração, atua em diferentes setores, desde o segmento supermercadista até o segmento de abate de gado, sendo que o faturamento das empresas que atuam no segmento supermercadista, que será o foco desta pesquisa, girava em torno de $\mathrm{R} \$ 40$ milhões por ano.

Com o crescimento do grupo nos últimos anos, dois problemas surgiram: os sócios já se encontravam bastante saturados de trabalho, já que não havia delegação de responsabilidades em relação à tomada de decisão, seja esta estratégica ou operacional; e a sucessão da administração, já que os sócios não tinham preparado a segunda geração para assumir a direção do grupo. 
Inicialmente, um dos sócios propôs a profissionalização do grupo, sendo que os demais sócios concordaram que esta seria a melhor alternativa, frente ao cenário no qual estavam inseridos.

Foi contratado um executivo especializado na profissionalização de grupos familiares, que propôs a criação de uma superintendência do grupo, e de um conselho de administração.

A superintendência seria ocupada provisoriamente pelo novo executivo, que seria subordinado unicamente ao conselho de administração, formado por três dos cinco sócios, que demonstraram interesse em continuar na gestão do grupo, e pelo superintendente.

Formado o conselho de administração, foi elaborado um organograma formal, incluindo todos os negócios do grupo, o qual foi formalizado perante todos os funcionários, que passaram a se reportar para suas chefias imediatas, ao invés de se reportarem sempre para os sócios, como vinha ocorrendo.

Este organograma era formado na alta hierarquia pelo conselho de gestão, pela superintendência e pelos diretores de desenvolvimento organizacional, financeiro, de logística e comercial, sendo que cada um destes setores possuía gerências em cada um dos negócios do grupo, e que estas gerências eram diretamente subordinadas ao diretor respectivo.

Cada um dos diretores possuía elevada autonomia, e se reportavam apenas para o superintendente, que tratava de levar os assuntos mais importantes para deliberação do conselho.

Como não havia controle sério em relação à movimentação financeira dos sócios com o capital do grupo e entre as diferentes unidades de negócios do grupo, foi contratada uma consultoria contábil para auditar as contas e organizar os processos internos de movimentação financeira.

As movimentações de dinheiro, que antes eram realizadas pelos sócios ou demais parentes, passaram a ser concentradas nos funcionários do setor financeiro, de modo a organizar as contas da empresa.

Para integrar as diferentes unidades de negócios, foi implantado um software ERP, que permitiu com que cada diretor pudesse acompanhar o resultado de seus gerentes e que favoreceu o compartilhamento de informações e recursos entre as empresas do grupo.

Para otimizar a utilização da estrutura de desenvolvimento organizacional, foi criado um centro de treinamento comum para os colaboradores do grupo, para capacitação de todos os funcionários das diversas empresas do grupo.

Em relação às empresas do setor supermercadista, algumas mudanças podem ser visualizadas no quadro 02.

Dentre as mudanças que ocorreram nas empresas do setor supermercadista do grupo $B$, três merecem destaque: mudança dos fornecedores, ajuste da política salarial e redução da ruptura.

As compras, que antes eram realizadas frente a distribuidores e atacadistas (cerca de $90 \%$ do total das compras), passaram a ser negociadas, pelo menos em $50 \%$, diretamente com a indústria. Compradores pouco eficientes ou que insistiram em comprar apenas de distribuidores foram substituídos, de modo a profissionalizar este setor.

A política salarial, que variava tanto em relação a uma mesma função dentro de uma mesma loja, quanto em relação à mesma função nos diferentes supermercados, foi ajustada, de modo a reduzir as desigualdades que causavam insatisfação dos colaboradores. Além disso, as horas extras, que eram uma despesa elevada em relação à folha de pagamentos, foram reduzidas ao mínimo necessário, o que gerou economias significativas.

A ruptura, ou falta de itens para atender aos clientes, sofreu forte redução, já que o software ERP passou a ser utilizado para gerenciar o giro dos itens e pontos de reposição, garantindo uma gestão dos estoques mais eficaz e eficiente.

A cultura organizacional, arraigada no relacionamento individual patrão-empregado, foi substituída por um sistema de unidade de comando e delegação, o que possibilitou aos sócios o desligamento de tarefas operacionais.

Os proprietários passaram a focar seus esforços em assuntos estratégicos, apoiados pela implementação de um sistema de controle de resultados baseado na comparação orçado-realizado. 
Quadro 02 - Antes e depois da profissionalização do grupo

\begin{tabular}{ll}
\hline Antes & Depois \\
\hline Mudanças constantes no layout das lojas & Layout moderno e melhor planejado \\
Muitas horas extras de trabalho durante o mês & Ajuste da mão de obra à necessidade de trabalho \\
Ruptura elevada & Redução da ruptura \\
Colaboradores com pouco conhecimento funcional & Colaboradores com domínio das funções exercidas \\
Poucos check-outs e muitas filas & Aumento de mais de 70\% do número de check-outs \\
Estoque elevado & Estoque com alto giro \\
Compras realizadas por meio de distribuidores & Compras realizadas frente às indústrias \\
Política salarial desajustada & Política salarial mais justa entre os supermercados \\
\hline
\end{tabular}

Fonte: elaborado pelos autores com base nesta pesquisa

A segunda geração de proprietários foi alocada em diferentes funções no grupo, de modo que fossem adquiridas competências necessárias para que posteriormente assumissem o controle da organização.

Cabe ressaltar que uma dificuldade observada foi a falta de cooperação da média gerência, que quebrava o fluxo de comunicação, já que estes gerentes não eram acostumados a prestar contas de suas decisões.

Outra ressalva que deve ser mencionada diz respeito à falta de comprometimento de fato dos sócios, que, ao descentralizarem a responsabilidade acerca de tarefas operacionais, sentiam-se inseguros, já que trabalhavam predominantemente com o modelo mental de concentração absoluta de poder.

Finalmente, após os sócios aderirem de fato ao processo, e alguns colaboradores resistentes serem substituídos, o processo continuou a ser implementado, de maneira a atingir os objetivos previamente traçados.

\section{Discussão}

Depois de apresentar os estudos de casos desenvolvidos nesta pesquisa, segue uma discussão acerca de alguns aspectos relevantes nos processos de profissionalização da gestão familiar das empresas varejistas estudados, que será estruturada em forma de proposições centrais que destacam os principais pontos identificados até aqui.

Deve-se pontuar que todas as proposições enunciadas aqui foram baseadas em autores pesquisados no referencial teórico deste trabalho.

Proposição no 1: Empresas varejistas de pequeno e médio porte, cuja administração é familiar, carecem de planejamento e tendem a concentrar decisões operacionais nos proprietários.

De acordo com Grzybovski (2002), empresas familiares são marcadas pela centralização na tomada de decisão, e, conforme explica Gonçalves (2000), neste tipo de empresa falta planejamento focado no longo prazo.

Como pode ser observado nas organizações estudadas, os proprietários de empresas que não profissionalizaram sua gestão, ou seja, que administravam as organizações com base em uma estrutura familiar e informal, tendem a concentrar a tomada de decisão de todos os níveis, ou seja, desde decisões de cunho estratégico, até decisões operacionais.

Isso ocorre porque os sócios não conseguem delegar funções, seja pela estrutura gerencial rudimentar, seja pela falta de confiança nos colaboradores. Desta maneira, todas as decisões passam pelos proprietários, o que tem como consequência a falta de análise estratégica do ambiente e planejamento de ações para médio e longo prazo, pois os sócios, ao invés de se preocuparem com assuntos estratégicos, consomem esforços em gerenciar atividades operacionais e rotineiras.

Além disso, por causa da concentração de todas as decisões e controle nos proprietários, este controle e a tomada de decisão tendem a ser mais informais, o que dificulta na atribuição de responsabilidades e cobrança de funcionários, que sempre tendem a apontar outros como responsáveis, já que não há delimitação clara e formal de atribuições. Os colaboradores tornam-se omissos e se esquivam de qualquer cobrança.

Caso a organização insista em manter sua gestão familiar, a tendência é perder a diretriz que guia o crescimento dos negócios, o que gera, em última instância, perda da habilidade de inovar em práticas gerenciais e de trabalhar de maneira pró-ativa em relação aos desafios macro-ambientais. 
Proposição no 2: No processo de profissionalização de empresas familiares de pequeno e médio porte, deve ser desenhado ou reestruturado o organograma formal da empresa, para possibilitar a desconcentração de atribuições e responsabilidades.

Lussier e Sonfield (2004) argumentam que, na medida em que a empresa cresce e tende à profissionalização de sua gestão, torna-se crítico o uso de ferramentas formais de gestão, entre elas, a estruturação formal do organograma da empresa.

Neste sentido, uma preocupação central e imediata em um processo de profissionalização da gestão da empresa deve ser a formalização de um organograma, o qual deverá indicar a estrutura de comando a ser implementada na organização, para permitir que as decisões somente sejam levadas ao nível dos sócios caso haja relevância suficiente. Caso contrário, as decisões devem ser tomadas pelos funcionários de níveis hierárquicos inferiores.

Desta forma, é criada uma estrutura que favorece a delegação de responsabilidades e autoridade a colaboradores de nível operacional, o que diminui a carga de trabalho dos sócios, que passam a se preocupar com o planejamento da organização.

Se não há uma estrutura hierárquica previamente estabelecida, consequentemente não há uma linha de comando, e os sócios tendem a concentrar as decisões.

Além disso, deve-se destacar a importância de, ao se formalizar o organograma da empresa, garantir a criação de cargos de direção, que terão como principal função compartilhar com os proprietários as responsabilidades estratégicas, de planejamento e controle gerenciais.

Proposição no 3: A média gerência, que passa a ter de prestar contas, é um foco potencial de resistência à profissionalização da gestão empresarial.

Conforme explica Robbins (2004), em processos de mudança organizacional, grupos que terão sua autoridade reduzida na empresa tendem a apresentar certa resistência à implementação das mudanças propostas.

Com a profissionalização da gestão de uma empresa, o nível de controle tende a aumentar, juntamente com o nível de cobrança. Isso ocorre porque, ao ser criada uma estrutura hierárquica, cada colaborador passa a ter claramente definidas suas atribuições e responsabilidades, o que facilita na definição de responsáveis e cobrança de colaboradores ineficientes ou omissos.

Sem esta estrutura hierárquica, os colaboradores conseguem eximir-se com maior facilidade de seus erros ou omissões, atribuindo sempre a terceiros possíveis falhas.

Sendo assim, analisando as duas organizações apresentadas, pode-se visualizar que a média gerência tende a representar um obstáculo para a profissionalização da administração das empresas, pois, além de terem que responder diretamente por suas falhas, ainda passam a ter que prestar contas de suas decisões, o que evidencia gerentes competentes e gerentes irresponsáveis.

A média gerência deve ser monitorada durante o processo, já que esta deve servir como uma 'ponte' entre a alta administração e o nível operacional, mas que pode minar os esforços de profissionalização, para garantir a manutenção do status quo.

Apenas como reflexão, deve-se citar que, ao afirmar que o nível de controle aumenta, os autores referem-se não ao controle das atividades operacionais, mas sim ao controle dos resultados obtidos, que passam a ser atribuídos diretamente aos gerentes responsáveis.

Proposição no 4: A transparência, apoiada na comunicação efetiva, facilita a mudança organizacional e a delegação de responsabilidades em um processo de profissionalização da gestão da empresa.

Segundo Kotter (1997), qualquer mudança organizacional deve ser comunicada de maneira eficaz para todos os envolvidos. Para Walker, Armenakis e Bernerth (2007), uma mensagem eficaz deve ser bastante transparente no sentido de esclarecer, para todos os envolvidos no processo de mudança, a relação entre o estado atual e o desejado e como a mudança proposta é apropriada para eliminar a diferença entre ambos, além de explicitar os benefícios e pontos negativos, para os colaboradores, resultantes da mudança.

Um processo de profissionalização contém um certo grau de complexidade, por envolver atribuições de poder e responsabilidades, alterando status e autoridade de diversas personagens organizacionais. 
Por isso, a transparência ganha papel fundamental neste tipo de processo, pois garante que os colaboradores entendam quais as mudanças que estarão ocorrendo, e como as mesmas afetarão suas rotinas.

Esta transparência, embasada na comunicação sincera e realista, minimiza os temores organizacionais que geralmente atrapalham processos de mudança organizacional. Os colaboradores passam a trabalhar a favor do processo, a partir do momento em que entendem suas implicações gerenciais.

Também deve haver transparência na demissão de funcionários que não se adaptaram ao novo paradigma organizacional, para evitar que a desconfiança permeie o ambiente empresarial, e que sejam desenvolvidas atitudes negativas quanto ao processo.

Proposição no 5: Se os sócios não estiverem comprometidos, o processo não conseguirá obter êxito, pois depende daqueles abrir mão do controle em excesso, para ganhar em planejamento e visão sistêmica.

Kotter (1997) explica que, para que uma mudança seja implementada com sucesso, deve ser formada uma coalização de pessoas com autoridade suficiente para liderar estas mudanças, sendo estas pessoas, no caso das empresas familiares, os sócios.

Além disso, Daily e Dollinger (1992) pontuam que os sócios devem passar a confiar mais em procedimentos internos de controle, ao invés de concentrarem as atividades de controle gerencial. E, finalmente, Lussier e Sonfield (2004) destacam a importância, na profissionalização da gestão de empresas familiares, do planejamento de longo prazo.

A profissionalização da gestão familiar de determinada empresa começa com a decisão dos sócios de criar um sistema profissional que substitua o antigo sistema informal de tomada de decisão.

Assim, caso não haja comprometimento dos sócios, os mesmos persistirão em manter o controle sobre cada tarefa operacional (controle em nível micro), e o planejamento continuará a figurar em segundo plano.

Cabe aos sócios apoiar a criação de uma estrutura hierárquica de atribuições e responsabilidades, e abrir mão do controle em nível micro, de modo a concentrar seus esforços no desenvolvimento de diretrizes organizacionais, no planejamento de médio e longo prazo e no controle macro (sobre resultados).

Ao optarem pelo controle macro, apesar de haver inicialmente um sentimento de insegurança, pela falta de informações detalhadas acerca das rotinas organizacionais, os proprietários passam a obter maior confiança, ao desenvolverem uma visão sistêmica da empresa. Mas, para que isso ocorra, aqueles devem estar dispostos a iniciar o processo.

Proposição no 6: O processo de profissionalização favorece a modernização das práticas adotadas no varejo, pois é criada uma estrutura que favorece a implementação de melhorias, antes não visualizadas pelos proprietários, muitas vezes leigos na administração do varejo.

Segundo Upton, Teal e Felan (2001), a dinâmica de crescimento pode exigir da empresa familiar competências de planejamento estratégico para sustentar este processo de crescimento, bem como competências de gestão profissional do negócio para garantir o alcance dos seus objetivos e continuidade no longo prazo, o que faz com que seja necessária a inclusão na direção da empresa de profissionais especialistas em gestão.

Neste sentido, enquanto a direção da empresa encontra-se concentrada nos sócios, os mesmos, seja por falta de know how técnico, seja pela falta de foco nas decisões estratégicas e táticas, não implementam práticas de gestão modernas, que otimizariam a rentabilidade da organização.

Quando os sócios carecem de conhecimento acerca das práticas de gestão varejista modernas, há uma tendência a se ignorar inovações nos processos gerenciais, o que minimiza os ganhos organizacionais, e até mesmo reduz a capacidade competitiva da empresa.

Outra situação igualmente danosa é a existência de sócios conhecedores das técnicas de gestão modernas, mas que despendem tempo excessivo em tarefas operacionais, o que reduz os esforços dedicados para a implementação de melhorias gerenciais de cunho tático e estratégico. Neste cenário, os proprietários, por conhecerem administração, não vêem necessidade de criar um sistema de compartilhamento de autoridade ou estruturar a tomada de decisão, por acreditarem que conseguem 
administrar sozinhos, o que favorece a concentração das decisões, que acaba por privilegiar o operacional em detrimento do tático e estratégico.

A partir do momento em que os sócios se abrem para a estruturação de um sistema de gestão profissional, a implementação de práticas gerenciais modernas é facilitada, pois a troca de informações entre os sócios e os demais profissionais eleva a tomada de decisão a níveis racionais e planejados, em detrimento da informalidade e irracionalidade.

Proposição no 7: Faz parte do processo de profissionalização a implementação de um sistema de controle gerencial, de modo que seja possível para a alta direção acompanhar o desempenho das atividades descentralizadas.

Conforme explicam Daily e Dollinger (1992), à medida que as empresas passam a ser geridas profissionalmente, passa-se a confiar mais nos procedimentos de controle interno, e, segundo Lussier e Sonfield (2004), estes procedimentos de controle interno são necessários à medida que há uma maior descentralização da tomada de decisão.

Assim, em um processo de profissionalização da gestão de determinada empresa, faz-se necessário desenvolver um sistema que permita aos sócios e aos executivos o monitoramento dos resultados das rotinas operacionais.

Deve-se destacar que, ao contrário do controle excessivo focado nas atividades operacionais que ocorre na gestão familiar, ao profissionalizar a gestão organizacional, o foco passa a ser o monitoramento dos resultados e indicadores operacionais, e não mais na execução propriamente dita.

Este monitoramento tem duas funções: garantir aos sócios determinado nível de controle e aos executivos, possibilidade de agir para solucionar possíveis problemas.

Em relação ao controle dos sócios, pode-se dizer que este sistema de monitoramento de indicadores e resultados reduz a insegurança intrínseca ao processo de delegação de autoridade e responsabilidades. Os sócios abrem mão de controle direto, mas ainda detém certo nível de controle acerca dos resultados obtidos. Desta forma, há um equilíbrio entre delegação e controle.

Já em relação ao controle dos executivos, é importante que haja um sistema de monitoramento dos resultados operacionais, de maneira que quaisquer desvios que possam comprometer as metas traçadas possam ser identificados em tempo ágil, de modo a possibilitar o desenvolvimento de soluções eficazes.

Proposição no 8: A profissionalização da gestão de empresas familiares é um processo top-down.

Para Lodi (1989), empresas familiares, depois de atingirem seu apogeu, passam a sofrer forte declínio em seu desempenho, caso não optem por profissionalizar sua gestão, sendo a decisão pela profissionalização, segundo Lussier e Sonfield (2004), responsabilidade dos sócios.

Além disso, conforme pontua Kotter (1997), uma mudança organizacional, seja ela qual for, envolve mudanças também na cultura organizacional, sendo que estas mudanças culturais é que garantirão a continuidade das novas práticas.

Pode-se perceber que o processo de profissionalizar a gestão de uma empresa, que estava acostumada ao sistema familiar de administração, envolve principalmente mudança de paradigmas organizacionais.

o controle excessivo nas tarefas operacionais é substituído pelo controle macro e pelo planejamento estratégico e tático; a tomada de decisão sem critérios claros ou diretrizes previamente definidas passa a ser um processo racional, que equilibra o feeling dos sócios e as estratégias formais delimitadas; o papel paternalista dos sócios desaparece, sendo que os mesmos passam a ocupar papéis de dirigentes e planejadores, o que tem como resultado a maior autonomia dos funcionários, que evoluem mais como profissionais.

A cultura da organização passa a focar a autonomia seguida da prestação de contas, o planejamento e a formalização de processos, sendo que tudo isso deve ser alinhado ao rumo desejado pelos sócios para a organização.

Sendo assim, o processo de profissionalização deve ser iniciado e gerenciado pela alta administração, englobando executivos contratados e proprietários, que deverão traduzir a direção desejada para a organização em uma nova política de negócios, que deverá guiar toda e qualquer mudança nos paradigmas organizacionais. 


\section{Conclusões}

Este artigo abordou o processo de profissionalização da gestão de empresas familiares que atuam no segmento varejista, de modo a identificar as implicações gerenciais e benefícios deste processo.

Foram apresentados dois estudos de casos de grupos varejistas que optaram por profissionalizar sua gestão, e, posteriormente, foram desenvolvidas algumas proposições centrais acerca deste processo de profissionalização.

Como conclusões, pode-se constatar que a iniciativa rumo à gestão mais profissional dos negócios deve partir dos sócios da organização, que devem estar cientes da mudança de paradigma necessária nas práticas de gestão adotadas, já que o controle das atividades operacionais deverá ser substituído pelo controle de resultados e pelo planejamento, e depende dos sócios abrir mão do antigo controle informal de cada operação, rotineira ou não.

Além disso, pode-se constatar vários benefícios decorrentes indiretamente do processo de profissionalização, como redução dos estoques, negociações melhores com os fornecedores e menores custos das mercadorias vendidas, políticas de salários mais ajustadas, funcionários mais preparados, devido ao treinamento recebido, entre outros. São benefícios indiretos, pois não ocorrem com a profissionalização, mas por causa da profissionalização, já que a nova estrutura administrativa facilita a implementação de ações e práticas mais modernas de gestão, que são responsáveis pelos benefícios citados.

Deve-se destacar também a importância da criação de um sistema de controle gerencial, que permita aos sócios e executivos monitorarem os resultados operacionais, e, ao mesmo tempo, criar indicadores que sinalizem necessidade de intervenção nos níveis das operações, já que aquela fica restrita apenas a situações extremas.

Uma consideração importante é que profissionalizar a gestão não é excluir os sócios do processo de tomada de decisão, mas sim realocá-los a funções de direção e planejamento, desvinculando-os de atividades operacionais.

Também se deve ressaltar aqui que, em um processo de profissionalização gerencial, deve ser desenvolvida uma estrutura hierárquica formal de atribuição de responsabilidades e autoridade, de modo a descentralizar a tomada de decisão dos sócios. Esta estrutura deve permitir um maior grau de formalidade nos relacionamentos internos, eliminando eventuais situações nas quais não se encontram culpados, pois não havia atribuições claras de responsabilidade.

Finalmente, deve-se citar que o processo de profissionalização geralmente segue um fluxo top-down, pois cabe aos sócios e executivos estabelecer a nova estrutura organizacional. $E$, para garantir que os funcionários operacionais e da média gerência não confrontem o processo, deve haver sempre transparência e comunicação dos objetivos pretendidos, das mudanças que estarão sendo realizadas e de como as mesmas afetarão suas rotinas, o que reduz significativamente a resistência ao processo de profissionalização.

Esta pesquisa tem como limitação o fato de ter trabalhado apenas com duas organizações. No entanto, pelo número reduzido da amostra, foi possível aos pesquisadores um nível mais aprofundado de estudo dos processos de profissionalização acompanhados.

Para finalizar, este trabalho resultou em uma série de proposições acerca do processo de profissionalização da gestão de empresas familiares que atuam no segmento supermercadista, que devem ser testadas em pesquisas futuras em outras empresas, de portes diferentes, que passaram pelo mesmo processo e que atuam em outros ramos de atividade, de maneira a testar sua validade e alcance.

\section{Referências}

BERNHOEFT, R. Como criar, manter e sair de uma sociedade familiar (sem brigas). São Paulo: SENAC, 1996.

CHIAVENATO, I. Os novos paradigmas: como as mudanças estão mexendo com as empresas. São Paulo: Atlas, 1996.

CHITTOOR, R.; DAS, R. Professionalization of management and succession performance: a vital linkage. Family Business Review, v. 20, n. 1, p.65-78, 2007. doi:10.1111/j.1741-6248.2007.00084.x 
CHUA, J. H.; CHRISMAN, J. J.; SHARMA, P. Defining the family business by behavior. Journal of Entrepreneurship: Theory and practice, v. 23, n. 4, 1999.

COOPER, D. R.; SCHINDLER, P. S. Métodos de pesquisa em administração. 7. ed. Porto Alegre: Bookman, 2003.

DAILY, C. M.; DOLLINGER, M. J. An empirical examination of ownership structure in family and professionally managed firms. Family Business Review, v. 5, n. 2, p.117-136, 1992. doi:10.1111/j.1741-6248.1992.00117.x

DONNELLEY, R. G. A empresa familiar. Revista de Administração de Empresas, v. 7, n. 23, p. 161-198, out./dez., 1967.

GIL, A. C. Métodos e técnicas de pesquisa social. 5. ed. São Paulo: Atlas, 2001.

GONÇALVES, J. S. R. C. As empresas familiares no Brasil. Revista de Administração de Empresas, v. 7, n. 1, p. 7-12, jan./mar., 2000.

GRZYBOVSKI, D. O administrador na empresa familiar: uma abordagem comportamental. Passo Fundo: UPF Editora, 2002.

KOTLER, P. Administração de marketing: a edição do novo milênio. São Paulo: Prentice Hall, 2000.

KOTTER, J. P. Liderando mudanças. 19. ed. Rio de Janeiro: Elsevier, 1997.

LEE, J. The effects of family ownership and management on firm performance. SAM Advanced Management Journal, v. 69, n. 4, 2004.

LEONE, N. M. G.; SILVA, A. B.; FERNANDES, C. B. Sucessão: como transformar o duelo em dueto. Revista de Administração da Universidade de São Paulo, v. 31, n. 3, p. 76-81, jul./set., 1996.

LEVY, M.; WEITZ, B. A. Administração de varejo. São Paulo: Atlas, 2000.

LEWIN, K. Group decision and social change. In: SWANSON, G. E.; NEWCOMB, T. M.; HARTLEY, E. L. (EdS.). Readings in social psychology. New York: Holt, 1952. p.459-473.

LODI, J. B. O fortalecimento da empresa familiar. 3. ed. São Paulo: Pioneira, 1989.

LUSSIER, R. N.; SONFIELD, M. C. Family business management activities, styles and characteristics: a correlational study. American Journal of Business, v. 19, n. 1, p. 47-53, 2004.

MCGOLDRICK, P. J. Retail marketing. Londres: MCGraw-Hill, 2002.

MEGGINSON, L. C.; MOSLEY, D. C.; PIETRI, P. H. Management: concepts and applications. New York: HaperCollins, 1991.

MOTTA, P. R. Transformação organizacional: A teoria e a prática de inovar. Rio de Janeiro: Qualitymark, 1997.

OLIVEIRA, D. P. R. Empresa familiar: como fortalecer o empreendimento e otimizar o processo sucessório. São Paulo: Atlas, 1999.

PARENTE, J. Varejo no Brasil: gestão e estratégia. São Paulo: Atlas, 2009.

ROBBINS, S. P. Fundamentos do comportamento organizacional. 7. ed. São Paulo: Pearson, 2004.

SANTOS, A. M. M. M.; COSTA, C. S. Características gerais do varejo no Brasil. BNDES Setorial, 1997. Disponível em: <www.bndes.gov.br/ conhecimento/publicacoes/ catalogo/ setor2.asp>. Acesso em: 15 fev. 2009.

STEIER, L. P.; WARD, J. L. If theories of family enterprise really do matter, so does change in management education. Journal of Entrepreneurship: Theory and Practice, v. 30, n. 6, 2006, p. 887-895. doi:10.1111/j.1540-6520.2006.00159.x

UPTON, N.; TEAL, E. J.; FELAN, J. T. Strategic and business planning practices of fast growth family firms. Journal of Small Business Management, v. 39, n. 1, p. 60-72, 2001. doi:10.1111/0447-2778.00006

WALKER, H. J.; ARMENAKIS, A. A.; BERNERTH, J. B. Factors influencing organizational change efforts: an integrative investigation of change content, context, process and individual differences. Journal of Organizational Change Management, v. 20, n. 6, 2007. doi:10.1108/09534810710831000

YIN, R. K. Estudo de caso: planejamento e métodos. 3. ed. Porto Alegre: Bookman, 2005. 